\title{
COVID-19, anorexia nervosa and obese patients with an eating disorder - some considerations for practitioners and researchers
}

\author{
Mladena Simeunovic Ostojic ${ }^{1 *}$, Joyce Maas ${ }^{1,2}$ (D) and Nynke M. G. Bodde
}

\begin{abstract}
Since COVID-19 is a global health emergency, there is an urgent need to share experiences on decision-making with regard to safety recommendations and for hypotheses that can inform a more focused prevention and treatment. Moreover, combining research into eating disorders and obesity with research into COVID-19 may provide a unique opportunity to shed light on the susceptibility to COVID-19.
\end{abstract}

Keywords: COVID-19, Eating disorders, Anorexia nervosa, Obesity

To date, there are no case series available that report on associations between pre-existing eating disorders (ED) and COVID-19 due to, among other reasons, the lack of widespread testing, standardized data collection, and a potential sampling bias (i.e., having COVID-19 symptoms and being hospitalized increases the chances of being selected for testing). In the absence of current observational data on the incidence of COVID-19 in ED, a thorough knowledge of infection risk, common and uncommon manifestations of COVID-19, as well as an in-depth understanding of the clinical features and pitfalls in the diagnosis of viral infections in ED is of vital importance. Below, we briefly summarize the current data on the risk of COVID-19 in ED populations and propose recommendations for safety interventions and future research.

\footnotetext{
* Correspondence: m.simeunovic-ostojic@ggzoostbrabant.nl ${ }^{1}$ Center for Eating Disorders, Mental Health Center Region Oost-Brabant, Wesselmanlaan 25a, 5707, HA, Helmond, The Netherlands

Full list of author information is available at the end of the article
}

\section{The risk of COVID-19 infection in patients with ED - safety recommendations}

Several studies suggest that both obesity and underweight can increase the risk of viral infection in a Ushaped manner, which holds in particular for influenzarelated pneumonia [1]. Paradoxically, despite serious malnourishment and alterations in immune functions, it has been reported that anorexia nervosa (AN) seems to be associated with fewer symptomatic viral infections [2-4]. However, because of the paucity, contradictions and methodological shortcomings of previous studies [2-5], extreme care must be taken in drawing any firm conclusion.

As the incidence of asymptomatic viral infections in patients with AN has not been studied, it is unknown whether they are less susceptible to viral infections, or whether these patients have a normal or even increased susceptibility to infection with a more asymptomatic or mild disease course and an absence of conventional clinical markers of infection $[3,6]$. Indeed, it has been hypothesized that immune exhaustion in the context of persistent, spontaneously elevated levels of pro-inflammatory cytokines in AN may lead to an impaired capacity to mount an acute-phase response to

(c) The Author(s). 2021 Open Access This article is licensed under a Creative Commons Attribution 4.0 International License, which permits use, sharing, adaptation, distribution and reproduction in any medium or format, as long as you give appropriate credit to the original author(s) and the source, provide a link to the Creative Commons licence, and indicate if changes were made. The images or other third party material in this article are included in the article's Creative Commons licence, unless indicated otherwise in a credit line to the material. If material is not included in the article's Creative Commons licence and your intended use is not permitted by statutory regulation or exceeds the permitted use, you will need to obtain permission directly from the copyright holder. To view a copy of this licence, visit http://creativecommons.org/licenses/by/4.0/. The Creative Commons Public Domain Dedication waiver (http://creativecommons.org/publicdomain/zero/1.0/) applies to the data made available in this article, unless otherwise stated in a credit line to the data. 
infection under an extra stimulus ([7], for review). Additionally, one recent study revealed a significant negative genetic correlation between $\mathrm{AN}$ and the acute phase infection marker C-reactive protein (CRP) [8]. From a clinical point of view, this is of particular concern as asymptomatic acute viral infection does not preclude direct damage caused by viruses and consequently secondary bacterial infections, necessitating timely diagnosis and antibacterial therapy. Actually, a number of studies do confirm that AN is associated with increased morbidity and mortality due to delayed diagnosis of bacterial infections, occult sepsis and atypical infections $[3,6$, 9-11]. Indeed, and commonly seen, a reduced or absent fever and CRP response, and a delayed leukocytosis may contribute to delays in the diagnosis of infection in $\mathrm{AN}[3$, 6]. In addition, AN may have clinical features that can mimic COVID-19, such as gastrointestinal symptoms, syncope, myalgias, and fatigue. Furthermore, laboratory abnormalities such as lymphopenia, thrombocytopenia, abnormal liver function and elevated ferritin, interleukin 6 (IL-6), and creatine kinase levels can be seen in COVID-19 [12, 13], but are also associated with AN [14]. To further add to the complexity, using body temperature for detecting acute infection in AN during refeeding is difficult because of lower basal body temperature, blunted fever response, but increased production of body heat during renutrition [15]. This suggests that the standard temperature threshold $\geq 37.8^{\circ} \mathrm{C}$ for infection no longer holds, and that a temperature elevation of $\geq 1.1^{\circ} \mathrm{C}$ for defining fever [16] must be interpreted in the context of the possible thermic effect of renutrition in AN. Importantly, resting energy expenditure increases by $10 \%$ during asymptomatic viral infection [17], and in symptomatic infection fever increases energy requirements by $10-13 \%$ for each degree of temperature increase. The hosts' ability to endure the infection-related (hyper) metabolism may well be affected by their insufficient energy-nutrient intake and low body reserves, and might be additionally hampered by COVID-19's gastrointestinal symptoms.

A particular concern exists regarding the vulnerability of patients through different stages of recovery. The clinical features of COVID-19 infection vary from asymptomatic to critical illness, with the latter associated with overactive inflammatory immune responses, leading to a cytokine storm and acute respiratory distress syndrome (ARDS) [12]. The association between COVID-19 and intense cytokine release raises the possibility that the "immunosuppressed" patient with acute AN is paradoxically protected or may at least not be predisposed to a poorer outcome. Indeed, most of the literature to date indicates that unlike other viral agents, COVID-19 seems not to be more severe in immunosuppressed patients although contradictory results have emerged depending on various other factors and the underlying cause of immune suppression (including the specific disease and treatment, the time of application, as well as the type and dose of medication) (e.g., [18-20]). Based on previous research (e.g., [20]), it is not unreasonable to believe that patients with acute AN are not immune to COVID19 , and when infected, especially if presenting an asymptomatic and mild disease, as it seems to be likely, they may be underdiagnosed. Conversely, since an aberrant inflammatory profile is recently found to be a state marker associated with acute AN and/or low BMI (i.e., which was not seen in those who had recovered from AN) [21], infection could be reactivated during the recovery phase, in particular during the refeeding process. Hypothetically, it might have occurred due to a suboptimal control of COVID-19 infection during acute AN (silent infection), leading to impaired viral clearance, and allowing a second episode of viral replication and/or a greater immune activity and consequently clinical infection during renutrition. On the one hand, refeeding could be helpful as it increases the number of circulating lymphocytes, which should improve the defence against the viral infection; but on the other hand, it could also be harmful as with refeeding sequestered infected lymphocytes could be released into the bloodstream, and as the circulating viral load increases, the disease reactivates. In line with this, several reports show impaired viral clearance and COVID-19 reactivation in patients with compromised immune systems after withdrawal of some immunosuppressive drugs [22, 23]. Also, severe and atypical infections are among the features of the refeeding phase that are frequently reported in the literature, but are poorly understood and often overlooked [9]. Nevertheless, the association of nutritional status and refeeding with the risk and course of infections has attracted great research attention recently. Noteworthy, hypophosphatemia has been reported as an independent risk factor for the development of infections by impairing high-energy substrate availability for host defense $[24,25]$ and has been observed to correlate with lymphocyte count and severity of COVID-19 [26]. Additionally, one recent study demonstrated that the increased incidence of medical complications including infections in severe AN during the first 30 days of refeeding, compared with the 30 days prior to treatment and the second phase of treatment, is accounted for less by the starvation process per se, and more by a transient process of physiological adaptation to refeeding [27]. Furthermore, the first randomized controlled trial on refeeding among adult mechanically ventilated ICU patients found that caloric restriction significantly reduced the incidence of major infections, in particular respiratory infections [25]. Collectively, these findings reinforce the hypothesis that clinically overt and more severe COVID-19 infection could arise, at least in part, as a response to refeeding. Determining the possibility of asymptomatic infection, impaired viral clearance and 
reactivation of the virus has important implications for coping with COVID-19 in AN. Hence, a combination of cycle threshold values of RT-PCR reactions as direct measures of COVID-19 viral loads on different time courses of infection and immunodiagnostic serology tests is crucial for the interpretation of other accurate diagnostic methods. Because persistent detection of low viral load by RT-PCR may have little clinical implication as both 'live' and 'dead' viruses are detected, future research may wish to investigate viral culture for detecting clinically significant viral shedding in this patient population.

Conversely, obesity, defined as body mass index $(\mathrm{BMI})>30$, appears to be an independent risk factor for more severe COVID-19-related infection and mortality. Importantly, an increase of visceral adipose tissue (VAT) and fat mass percentage - and not only BMI - correlate positively with COVID-19 morbidity [28]. Angiotensinconverting enzyme 2 (ACE2) has been identified as the host cell-surface receptor for COVID-19, forming a basis for viral tropism in several cells including adipocytes. Although obesity does not appear to have an effect on ACE2 expression by adipocytes [29], increased numbers of ACE2-expressing cells, due to higher adipose tissue (AT) volume, may increase susceptibility to viral hostcell entry [28]. ACE2 may also be shed into circulation and may modify pulmonary susceptibility of obese people to SAR-CoV-2 infection [30]. As viral tropism for and utilization of $\mathrm{AT}$ as a reservoir has already been shown for many types of viruses (e.g., H5N1, adenovirus AD-36, HIV), it is speculated that obese patients infected with COVID-19 may be potentially more contagious than lean individuals [28]. In support of this hypothesis, one not yet published study [31] shows that the COVID19 virus can infect human adipocytes as well as that the viral load is three times higher in aged adipose cells.

Together, clinical evidence and research suggest that it is reasonable to assume that obese patients $(\mathrm{BMI}>30)$ with an ED and hospitalized severely malnourished patients with AN are at increased risk of developing a (silent) COVID-19 infection and suffer more complications. At the very least clinical vigilance should be raised when treating both patient groups.

After considering consequences of underdiagnosing COVID-19 on the individual level and the risk of nosocomial outbreaks, for both healthcare workers who provide direct care to inpatients and patients with AN considered for clinical admission, we advise preadmission RT-PCR testing even without clinical suspicions of infection and, in addition, when available and clinically indicated, antibody profile for patients. Since the sensitivity of RT-PCR, to date the 'gold standard' for the diagnosis of COVID-19, is moderate and asymptomatic patients may develop an infection during inpatient treatment, there is a need for daily clinical rescreening for signs and symptoms of infection and repeat testing on indication. Additionally, we recommend to educate patients to raise awareness of the need for screening and testing, and to avoid misinformation, fear and stigmatization. Undoubtedly, there are compelling reasons to effectively prevent the spread of COVID-19 in inpatient ED units. First, in congregate settings, COVID19 can spread rapidly so prompt identification of COVID-19 cases and implementation of prevention measures are critical to ensure the protection of other patients and staff members. A report from New York (USA) showed an overall rate of COVID-19 infection of $15.6 \%$, with an asymptomatic positive rate of $13.7 \%$ among patients in psychiatric inpatient settings from 1 March to 1 May 2020, which is higher than the $10.3 \%$ positivity in respiratory specimens from the broader US population at the same time [32]. Second, as mentioned above, reliance on the presence of symptoms to guide COVID-19 testing in AN can lead to under- or overdiagnosis. Also, several previously published reports of COVID-19 disease among psychiatric inpatients identified inconsistent and incomplete responses to survey questions because patients would often mention non COVID-19 like symptoms or attribute symptoms to existing comorbidities, leading to underdiagnosis in those who are COVID-19 positive, since both groups would not be tested on the basis of their survey responses. Additionally, it has been reported that only $26 \%$ of positive adolescent inpatients had typical symptoms [33]. Third, some recommended elements of contingency planning for psychiatric hospitals and residential settings, such as restricting dining to in-room meals instead of communal dining [32], are not feasible or therapeutic in AN inpatient settings.

In the outpatient setting patients should be screened regularly for symptoms and known exposure in between sessions. Indeed, several authors (e.g., [34]) recommend reducing the threshold for COVID-19 testing and, once vaccination is widely available, encouraging people with obesity to be vaccinated. Because the duration of virus shedding may be prolonged in obese outpatients having tested positive for COVID-19, the quarantine period for this population may need to be extended, with treatment comprised of telemedicine only.

There are currently more than 100 COVID-19 vaccine candidates under development. With astonishing speed, at least seven vaccines have achieved regulatory authorization or approval around the globe and there are at least 55 vaccine candidates in phase 1-3 clinical trials listed in the COVID-19 vaccine tracker of the Regulatory Affairs Professional Society (RAPS) site on 23 December 2020. All seven leading vaccines probably have a minimum $50 \%$ efficacy threshold, on the basis 
of clinical trial data so far. However, it is not clear how long the vaccines' protective effects last, whether it can block people from transmitting the virus or whether one vaccine works better than another in certain groups of people.

Since poor vaccine-induced immune responses have been observed in the obese (e.g., hepatitis B, influenza H1N1) [35], there were concerns that COVID-19 vaccines would not work well for obese people. Fortunately, data from the the Pfizer/BioNTech and the Moderna COVID-19 vaccine trials showed around 95\% efficacy in the participants at risk of severe COVID-19, including those with a $\mathrm{BMI} \geq 30[36,37]$. However, since conclusions about effectiveness are drawn from less than 200 participants with developed disease, more powered studies are needed to definitively confirm effects of vaccines across different demographics and conditions. Additionally, because vaccine supply will not be immediately available to immunize all who could benefit from vaccination, most countries have defined priority groups. For example, the provisional COVID-19 vaccine priority list, which outlines who will be given a vaccine first, published by Public Health England [38] is now divided into nine groups. People aged 16-65 with a BMI of 40 and above are in priority group six, meaning they will be prioritised for the vaccine ahead of healthy over-60s. Priority group six also includes adults aged 18-65 who suffer from other conditions considered to put them more 'at risk' for COVID-19. Although these include among others immunocompromised conditions and severe mental illness, AN is not yet treated as a priority group. Notably, currently there is no data yet on COVID-19 vaccine efficacy or safety in immunocompromised people. Nevertheless, The Centers for Disease Control and Prevention $(\mathrm{CDC})$ and The European Medicines Agency (EMA) recommend these patients may still receive the vaccine and should be counselled they may have a lower immune response than the general population, and that the safety profile is not currently known. Comparable recommendations regarding the possible benefits and risks of COVID-19 vaccine in patients with AN appears to be lacking. A pilot study of immunogenicity of H1N1 vaccination among 10 adults with AN found antibody levels to be similar to normal weight counterparts, but the study lacked a control group and the persistence of immune response was not evaluated [39]. Hence, patients with AN and their physicians need to use these limited data to weigh the benefits and risks of COVID-19 vaccines, taking into account the patient's specific risk for COVID-19. Importantly, as we cannot assume that data on one vaccine type in the obese and AN can be extrapolated to other vaccine types, it is therefore urgent that any COVID-19 vaccine studies include anthropomorphic measurements as a potential confounder for vaccine effectiveness. Companies that have developed COVID-19 vaccines may wish to include patients with AN in clinical trials and post authorization observational studies on vaccine use.

Together, research on viral detection, longitudinal follow-up of viral shedding, laboratory biomarkers (e.g., haematological markers, cytokines, immunoglobulins) and clinical manifestation and outcomes of COVID-19 in ED are necessary. To improve the understanding of the impact of COVID-19 infection on patients with ED, we strongly urge that all such patients be enrolled in patient (inter) national registries whenever possible. Data collection on patients with AN who received a COVID19 vaccine will be needed to provide information of immunogenicity, safety and the persistence of immune response to guide future vaccines recommendations. As additional information from clinical trials and from data collected on vaccinated patients with AN outside clinical trials becomes available, it will be critical that ED professionals stay well informed about emerging data, safety and efficacy of vaccines so that they can help patients make sound decisions.

\section{Insights derived from findings on immunity in AN and obesity - future research directions}

Striking similarities between the cytokine profile of COVID-19 infection and AN [12, 40], and recent findings on the role of T-cells in the immunity to COVID19 [41] and its hypothesized role in viral resistance in AN $[40,42]$ may inspire future research.

While the question whether patients with AN are indeed less prone to viral infections than individuals with simple malnutrition remains to be empirically confirmed, the most recent reviews on the relationship between AN and immunity posit that this interplay is unique and more complex than it is in primary malnutrition (PM) [42]. Unlike what is seen in PM, patients with AN show intact or increased $\mathrm{T}$-cell proliferation to various antigens, and an elevated $\mathrm{CD} 4 / \mathrm{CD} 8$ ratio, while especially memory CD8 T-cell counts seem to be lower. Speculatively, this is related to a perceived lack of symptomatic common viral infections, as a marked reduction in memory CD8 T-cells could lead to a reduction in lymphocytes subserving recall responses. Although the majority of studies on cytokines in AN have yielded mixed and, at times, contradicting results, the most recent studies propose a unique immunological profile of AN. Of particular interest, pro-inflammatory cytokines (IL-1, IL-6, and TNF) appear to be elevated in AN when compared to PM, while the levels of the antiinflammatory cytokine IL-10 seem to be significantly influenced by ED diagnosis and BMI (i.e., being higher in $\mathrm{AN}$ and normal-weight individuals and lower in bingeeating disorder and obesity) [43]. The overproduction of 
IL-10 and the down-regulation of pro-inflammatory cytokines could explain the absence of infection in AN.

Notably, several mechanisms that have been proposed to explain the relationship between obesity and COVID19, such as low-grade chronic inflammation, impaired memory CD8 + T-cell responses, increased circulating levels of pro-inflammatory cytokines and hyperleptinaemia, overlap and mirror pre-existing models of the unique immunological and metabolic profile in AN in an opposite direction. Since AT is established as an immunological organ and emerging research identified significant negative genetic correlations between AN and obesity ([44], for review), we argue that the question why obesity is a risk factor for COVID-19 is inherently an evolutionary question that could be addressed by looking at the "opposite side of the same coin", namely constitutional thinness, PM and possibly AN. Although constitutional thinness is a more evident "mirror image" of obesity than is AN and reconceptualization of AN as the opposite of obesity remains subject to vigorous debate, based on new genetic discoveries in $\mathrm{AN}$ it has been hypothesized that the conditions may represents "metabolic and microbiome bookends" [44]. Indeed, a genome-wide association study (GWAS) suggests that the genetic origins of AN are both metabolic and psychiatric. Additionally, the results indicated one GWAS-significant signal that has previously been linked to type-1 diabetes and autoimmune disorders, supporting an important new direction for research into some dimensions of speculative metabolic and immunological mirror images of AN and obesity ( [45], for review) that are shaped by evolutionary factors. Arguably, changes in food availability and infectious pathogens are probably among the strongest selective forces that act on the human genome. It has been hypothesized that infectious diseases favor investment in VAT because of its immune advantage in fighting infection [46], along with variable responses to specific infectious pathogens in terms of fat distribution and cytokine biology leading to the remarkable inter-individual and inter-population immune response and fat distribution heterogeneity [47]. Yet, some of the same mutations enabling humans to resist some infections also make us more prone to other infections and certain diseases, such as autoimmune disease, obesity and, possibly, AN. Although this assumption is not tested in AN, this hypothesis appears to be supported in other fields by evidence that having nonfunctional alleles of FUT2 protects against specific pathogens (e.g., Norovirus, Rotavirus, HIV) [48]. By contrast, the non-secretor phenotype has been also associated with increased susceptibility to other pathogens (e.g., Streptococcus pneumonia) and increased risk for certain autoimmune diseases, including type 1 diabetes and inflammatory bowel disease [48]. These examples serve to illustrate that the field of ED research could provide a unique opportunity to integrate the "metabolic and microbiome bookends" hypothesis of AN and obesity [44] and VAT-prioritization [46] and variable infectious disease selection hypotheses [47] into an overarching COVID-19 research framework aimed at investigating the susceptibility and resistance to virus infections in the whole spectrum of ED and obesity. A necessary first step will require prospective epidemiological, and clinical and laboratory studies on this subject. For example, examining whether variation of ACE2 expression, adipocyte viral tropism/load, viral shedding, serology markers, the cytokine and immune cells profile are different between the four major groups (obesity, constitutional thinness, simple malnutrition, AN /AN-R) could explain the differences in infection susceptibility.

\section{Conclusions}

The COVID-19 pandemic brings much uncertainty and many challenges for clinicians treating patients with ED. However, sharing experiences is the best way to learn real-time lessons and adapt to this rapidly changing pandemic. There are important questions crucial to our understanding of susceptibility to, clinical manifestation, course and outcomes of COVID-19 in AN and obese ED patients that need to be answered in order to inform our testing, treatment and vaccination policy. Since our knowledge about COVID-19 is still evolving, the presented recommendations may need to change and our perspective and hypotheses should be seen as a focus for discussion to inspire further research.

As obesity appears to be an independent risk factor for COVID-19 and we are facing two pandemics: the everexpanding obesity epidemic and the recent COVID-19 outbreak, we need to address both pandemics in the context of the genetic predisposition and the "obesogenic" niche applying modern evolutionary thinking. Combining research into AN and obesity with research into COVID-19 may provide a unique opportunity to study the susceptibility to COVID-19.

Given the low prevalence of AN and the widely dispersed but small patient base, efforts to engage the research and the patient communities to share their data are of critical importance. Creating a worldwide, shared database of viral and in particular COVID-19-related epidemiological, clinical (e.g., anthropomorphic measurement), laboratory and immunology data (e.g., serum cytokine changes, RT-PCR test results, antibody levels) in patients with ED and designing studies that explain the clinical observations may help to combat this and future pandemics. In addition, centralizing and integrating worldwide viral-related data with existing biobanks will be beneficial for future machine learning research to develop predictive diagnostic strategies and inform new hypotheses. 


\section{Abbreviations}

ACE2: Angiotensin-converting enzyme 2; AT: Adipose tissue; AN: Anorexia nervosa; AN-R: Recovered from anorexia nervosa; ARDS: Acute respiratory distress syndrome; BMI: Body mass index; CDC: Centers for disease control and prevention (CDC); CRP: C-reactive protein; ED: Eating disorder(s); EMA: European medicines agency; GWAS: genome-wide association study; PM: Primary malnutrition; RAPS: Regulatory affairs professional society; RTPCR: Reverse-transcription polymerase chain reaction; VAT: Visceral adipose tissue

\section{Acknowledgements}

We thank Anouk Gulpen (internist at Elkerliek Hospital, Helmond, the Netherlands) for her helpful comments and for proofreading our manuscript.

\section{Authors' contributions}

The literature search was carried out by $\mathrm{MO}, \mathrm{JM}$ and NB contributed to the writing. The author (s) read and approved the final manuscript.

\section{Funding}

Not applicable.

\section{Availability of data and materials}

Not applicable.

Ethics approval and consent to participate

Not applicable.

\section{Consent for publication}

Not applicable.

\section{Competing interests}

The authors declare that they have no competing interests.

\section{Author details}

${ }^{1}$ Center for Eating Disorders, Mental Health Center Region Oost-Brabant, Wesselmanlaan 25a, 5707, HA, Helmond, The Netherlands. 'Department of Medical and Clinical Psychology, Tilburg University, Warandelaan 2, P.O. Box 90153, 5000, LE, Tilburg, The Netherlands.

Received: 8 September 2020 Accepted: 11 January 2021

Published online: 20 January 2021

\section{References}

1. Dobner J, Kaser S. Body mass index and the risk of infection-from underweight to obesity. Clin Microbiol Infect. 2018;24:24-8. https://doi.org/ 10.1016/j.cmi.2017.02.013

2. Raevuori A, Lukkariniemi L, Suokas JT, Gissler M, Suvisaari JM, Haukka J. Increased use of antimicrobial medication in bulimia nervosa and bingeeating disorder prior to the eating disorder treatment. Int J Eat Disord. 2016; 49:542-52. https://doi.org/10.1002/eat.22497.

3. Brown RF, Bartrop R, Beumont $P$, Birmingham CL. Bacterial infections in anorexia nervosa: delayed recognition increases complications. Int J Eat Disord. 2005;37:261-5. https://doi.org/10.1002/eat.20135.

4. Brown RF, Bartrop R, Birmingham CL. Immunological disturbance and infectious disease in anorexia nervosa: a review. Acta Neuropsychiatr. 2008, 20:117-28. https://doi.org/10.1111/j.1601-5215.2008.00286.x.

5. Breithaupt L, Köhler-Forsberg O, Larsen JT, Benros ME, Thornton LM, Bulik $\mathrm{CM}$, et al. Association of exposure to infections in childhood with risk of eating disorders in adolescent girls. JAMA Psychiatry. 2019;76:800-9. https:// doi.org/10.1001/jamapsychiatry.2019.0297.

6. Birmingham CL, Hodgson DM, Fung J, Brown R, Wakefield A, Bartrop R, et al. Reduced febrile response to bacterial infection in anorexia nervosa patients. Int J Eat Disord. 2003;34:269-72. https://doi.org/10.1002/eat.10189.

7. Nova E, Samartin S, Gomez S, Morande G, Marcos A. The adaptive response of the immune system to the particular malnutrition of eating disorders. Eur J Clin Nutr. 2002;56:S34-7. https://doi.org/10.1038/sj.ejcn.1601482.

8. Tylee DS, Sun J, Hess JL, Tahir MA, Sharma E, Malik R, et al. Genetic correlations among psychiatric and immune-related phenotypes based on genome-wide association data. Am J Med Genet B Neuropsychiatr Genet. 2018;177:641-57. https://doi.org/10.1002/ajmg.b.32652
9. Webb GJ, Smith K, Thursby-Pelham F, Smith T, Stroud MA, Da Silva AN. Complications of emergency refeeding in anorexia nervosa: case series and review. Acute Med. 2011;10:69-76.

10. Devuyst O, Lambert M, Rodhain J, Lefebvre C, Coche E. Haematological changes and infectious complications in anorexia nervosa: a case-control study. QJM. 1993:86:791-9.

11. Guinhut M, Melchior J, Godart N, Hanachi M. Extremely severe anorexia nervosa: hospital course of 354 adult patients in a clinical nutrition-eating disorders-unit. Clin Nutr. 2020. https://doi.org/10.1016/j.clnu.2020.09.011.

12. Jamilloux $Y$, Henry T, Belot A, Viel S, Fauter M, El Jammal T, et al. Should we stimulate or suppress immune responses in COVID-19? Cytokine and anticytokine interventions. Autoimmun Rev. 2020:102567. https://doi.org/10. 1016/j.autrev.2020.102567.

13. Gupta A, Madhavan MV, Sehgal K, Nair N, Mahajan S, Sehrawat TS, et al. Extrapulmonary manifestations of COVID-19. Nat Med. 2020;26:1017-32. https://doi.org/10.1038/s41591-020-0968-3.

14. De Filippo E, Marra M, Alfinito F, Di Guglielmo ML, Majorano P, Cerciello G, et al. Hematological complications in anorexia nervosa. Eur J Clin Nutr. 2016:70:1305-8. https://doi.org/10.1038/ejcn.2016.115.

15. Marzola E, Nasser JA, Hashim SA, Shih PAB, Kaye WH. Nutritional rehabilitation in anorexia nervosa: review of the literature and implications for treatment. BMC Psychiatry. 2020;13:1-13. https://doi.org/10.1186/1471244X-13-290.

16. Fahed M, Barron GC, Steffens DC. Ethical and logistical considerations of caring for older adults on inpatient psychiatry during the COVID-19 pandemic. Am J Geriatr Psychiatry. 2020. https://doi.org/10.1016/j.jagp.2020. 04.027.

17. Kosmiski L. Energy expenditure in HIV infection. Am J Clin Nutr. 2011;94: 1677S-82S. https://doi.org/10.3945/ajcn.111.012625.

18. Thng ZX, De Smet MD, Lee CS, Gupta V, Smith JR, McCuskey PJ, et al. COVID-19 and immunosuppression: a review of current clinical experiences and implications for ophthalmology patients taking immunosuppressive drugs. Br J Ophthalmol. 2020. https://doi.org/10.1136/bjophthalmol-2020316586.

19. Fung M, Babik JM. COVID-19 in immunocompromised hosts: what we know so far. Clin Infect Dis. 2020:ciaa863. https://doi.org/10.1093/cid/ciaa863.

20. Minotti C, Tirelli F, Barbieri E, Giaquinto C, Donà D. How is immunosuppressive status affecting children and adults in SARS-CoV-2 infection? A systematic review. J Inf Secur. 2020;81:e61-6. https://doi.org/10. 1016/j.jinf.2020.04.026.

21. Nilsson IA, Millischer V, Göteson A, Hübel C, Thornton LM, Bulik CM, et al. Aberrant inflammatory profile in acute but not recovered anorexia nervosa. Brain Behav Immun. 2020. https://doi.org/10.1016/j.bbi.2020.05.024.

22. Gomez-Mayordomo V, Montero-Escribano P, Matías-Guiu JA, GonzálezGarcía N, Porta-Etessam J, Matías-Guiu J. Clinical exacerbation of SARS-CoV2 infection after fingolimod withdrawal. J Med Virol. 2020. https://doi.org/10. 1002/jmv.26279.

23. Gousseff M, Penot P, Gallay L, Batisse D, Benech N, Bouiller K, et al. Clinical recurrences of COVID-19 symptoms after recovery: viral relapse, reinfection or inflammatory rebound? J Inf Secur. 2020. https://doi.org/10.1016/j.jinf. 2020.06.073.

24. Olthof LE, Koekkoek WK, van Setten C, Kars JC, van Blokland D, van Zanten AR. Impact of caloric intake in critically ill patients with, and without, refeeding syndrome: a retrospective study. Clin Nutr. 2018;37:1609-17. https://doi.org/10.1016/j.clnu.2017.08.001.

25. Doig GS, Simpson F, Heighes PT, Bellomo R, Chesher D, Caterson LD, et al. Restricted versus continued standard caloric intake during the management of refeeding syndrome in critically ill adults: a randomised, parallel-group, multicentre, single-blind controlled trial. Lancet Respir Med. 2015;3:943-52. https://doi.org/10.1016/S22132600(15)00418-X.

26. Xue X, Ma J, Zhao Y, Zhao A, Liu X, Guo W, et al. Correlation between hypophosphatemia and the severity of Corona Virus Disease 2019 patients. medRxiv. 2020. https://doi.org/10.1101/2020.03.27.20040816.

27. Davies JE, Cockfield A, Brown A, Corr J, Smith D, Munro C. The medical risks of severe anorexia nervosa during initial re-feeding and medical stabilisation. Clin Nutr ESPEN. 2017;17:92-9. https://doi.org/10.1016/j.clnesp. 2016.09.005.

28. Huang Y, Yao L, Huang YM, Min W, Wei L, Yi S. Obesity in patients with COVID-19: a systematic review and meta analysis. Metabolism. 2020:154378. https://doi.org/10.1016/j.metabol.2020.154378. 
29. Radzikowska U, Ding M, Tan G. Distribution of ACE2, CD147, CD26 and other SARS-CoV-2 associated molecules in tissues and immune cells in health and in asthma, COPD, obesity, hypertension, and COVID-19 risk factors. Allergy. 2020;75:2829-45. https://doi.org/10.1111/all.14429.

30. Al Heialy S, Hachim MY, Senok A, Abou Tayoun A, Hamoudi R, Alsheikh-Ali $A$, et al. Regulation of angiotensin converting enzyme 2 (ACE2) in obesity: implications for COVID-19. bioRxiv. 2020. https://doi.org/10.3389/fphys.2020. 555039.

31. Agência FAPESP. https://agencia.fapesp.br/adipose-tissue-may-be-areservoir-for-sars-cov-2-brazilian-researchers-suggest/33729/. Accessed 6 Nov 2020. (2020)

32. Zhang E, LeQuesne $E$, Fichtel K, Ginsberg D, Frankle WG. In-patient psychiatry management of COVID-19: rates of asymptomatic infection and on-unit transmission. BJPsych Open. 2020, 2020;6. https://doi.org/10.1192/ bjo.2020.86.

33. Krass $P$, Zimbrick-Rogers $C$, Iheagwara C, Ford CA, Calderoni M. COVID-19 outbreak among adolescents at an inpatient behavioral health hospital. J Adolesc Health. 2020;67:612-4. https://doi.org/10.1016/j.jadohealth.2020.07.009.

34. Dicker D, Lev S, Gottesman T, Kournos T, Dotan M, Ashorov N, et al. A time frame for testing negative for SARS-COV2 in people with obesity. Obes Facts. 2020;13:528-33. https://doi.org/10.1159/000511738.

35. Painter SD, Ovsyannikova IG, Poland GA. The weight of obesity on the human immune response to vaccination. Vaccine. 2015;33:4422-9. https:// doi.org/10.1016/j.vaccine.2015.06.101.

36. FDA. Vaccines and Related Biological Products Advisory Committee Meeting December 10; 2020 [updated 2020, cited 2020 Dec 29]. Available from: https://www.fda.gov/media/144434/download

37. FDA. Moderna COVID-19 Vaccine; 2020 [updated 2020, cited 2020 Dec 29]. Available from: https:/www.fda.gov/media/144434/download

38. JCVI. Priority groups for coronavirus (COVID-19) vaccination: advice from the JCVI, 2 December 2020; 2020 [updated 2020, cited 2020 Dec 29]. Available from: https://www.gov.uk/government/publications/priority-groups-forcoronavirus-covid-19-vaccination-advice-from-the-jcvi-2-december-2020/ priority-groups-for-coronavirus-covid-19-vaccination-advice-from-the-jcvi-2december-2020

39. Zastrow A, Schnitzler P, Eckerle I, Herzog W, Friederich HC. Immunogenicity and safety of H1N1 vaccination in anorexia nervosa: results from a pilot study. Int J Eat Disord. 2012;45:146-9. https://doi.org/10.1002/eat.20908.

40. Dalton B, Bartholdy S, Robinson L, Solmi M, Ibrahim MA, Breen G, et al. A meta-analysis of cytokine concentrations in eating disorders. J Psychiatr Res. 2018;103:252-64. https://doi.org/10.1016/j.jpsychires.2018.06.002.

41. Grifoni A, Weiskopf D, Ramirez SI, Mateus J, Dan JM, Moderbacher CR, et al. Targets of T cell responses to SARS-CoV-2 coronavirus in humans with COVID-19 disease and unexposed individuals. Cell. 2020;181:1489-501. https://doi.org/10.1016/j.cell.2020.05.015.

42. Gibson D, Mehler PS. Anorexia nervosa and the immune system: a narrative review. J Clin Med. 2019;8:1915. https://doi.org/10.3390/jcm8111915.

43. Caroleo M, Carbone EA, Greco M, Corigliano DM, Arcidiacono B, Fazia G, et al. Brain-behavior-immune interaction: serum cytokines and growth factors in patients with eating disorders at extremes of the body mass index (BMI) spectrum. Nutrients. 2019;11:1995. https://doi.org/10.3390/ nu11091995.

44. Bulik CM, Flatt R, Abbaspour A, Carroll I. Reconceptualizing anorexia nervosa. Psychiatry Clin Neurosci. 2019;73:518-25. https://doi.org/10.1111/pcn.12857.

45. Mahon P, Hildebrandt T, Burdick K. New genetic discoveries in anorexia nervosa: implications for the field. Am J Psychiatry. 2017;174:821-2. https:// doi.org/10.1176/appi.ajp.2017.17050574.

46. West-Eberhard MJ. Nutrition, the visceral immune system, and the evolutionary origins of pathogenic obesity. Proc Natl Acad Sci U S A. 2019; 116:723-31. https://doi.org/10.1073/pnas.1809046116.

47. Wells JC. Ethnic variability in adiposity and cardiovascular risk: the variable disease selection hypothesis. Int J Epidemiol. 2009;38:63-71. https://doi.org/ 10.1093/ije/dyn183.

48. Smyth DJ, Cooper JD, Howson JM, Clarke P, Downes K, Mistry T, et al. FUT2 nonsecretor status links type 1 diabetes susceptibility and resistance to infection. Diabetes. 2011;60:3081-4. https://doi.org/10.2337/db11-0638.

\section{Publisher's Note}

Springer Nature remains neutral with regard to jurisdictional claims in published maps and institutional affiliations.

Ready to submit your research? Choose BMC and benefit from:

- fast, convenient online submission

- thorough peer review by experienced researchers in your field

- rapid publication on acceptance

- support for research data, including large and complex data types

- gold Open Access which fosters wider collaboration and increased citations

- maximum visibility for your research: over $100 \mathrm{M}$ website views per year

At BMC, research is always in progress.

Learn more biomedcentral.com/submissions 